\title{
Perianal embryonal rhabdomyosarcoma diagnosed by endoscopic ultrasound-guided fine needle
} \section{aspiration}

A 23-year-old man who was an illegal immigrant was admitted to our emergency unit, after a lengthy disembarkation process, with oliguria, constipation, vomiting, and abdominal pain. On admission, an abdominal ultrasound showed a bulky lesion $(16 \times 8 \mathrm{~cm})$ that was not clearly separable from the rectum with an inhomogeneous echotexture containing multiple anechoic areas.

To gain a better radiological assessment, a magnetic resonance imaging (MRI) scan was performed, which demonstrated a pelvic and lower abdominal lesion with a sagittal diameter of $25 \mathrm{~cm}$ and relatively sharp, convoluted edges. It extended from the rectum, where it was in the right paramedian position, to above the transverse umbilical line, where it was in contact with the ascending colon ( $\mathbf{F i g} \mathbf{1}$ ). However, the diagnosis remained uncertain and because of the need to stage the infiltration of the rectum and to spare the patient further radiation exposure, an endoscopic ultrasound-guided fine needle aspiration (EUS-FNA) was performed. A huge circumferential mass in the rectum, with inhomogeneous echotexture containing multiple anechoic areas consistent with areas of liquefaction was demonstrated ( Fig. 2).

Histological examination showed morphological and immunohistochemical appearances consistent with the diagnosis of embryonal rhabdomyosarcoma, botryoid variety.

Once the diagnosis had been made, the patient underwent palliative surgery (abdominoperineal amputation). The histological examination of the surgical specimen confirmed the diagnosis of embryonal rhabdomyosarcoma. Unfortunately, a few days after the surgical intervention, the patient died from postsurgical sepsis.

Rhabdomyosarcoma is an extremely rare malignancy of mesenchymal tissue origin. To date, only two other cases of primary rectal rhabdomyosarcoma and very few of perianal rhabdomyosarcoma have been described [1 -3]. Our work indicates that rhabdomyosarcoma should be considered as a rare differential diagnosis of an atypical rectal tumor in adults. Fur-

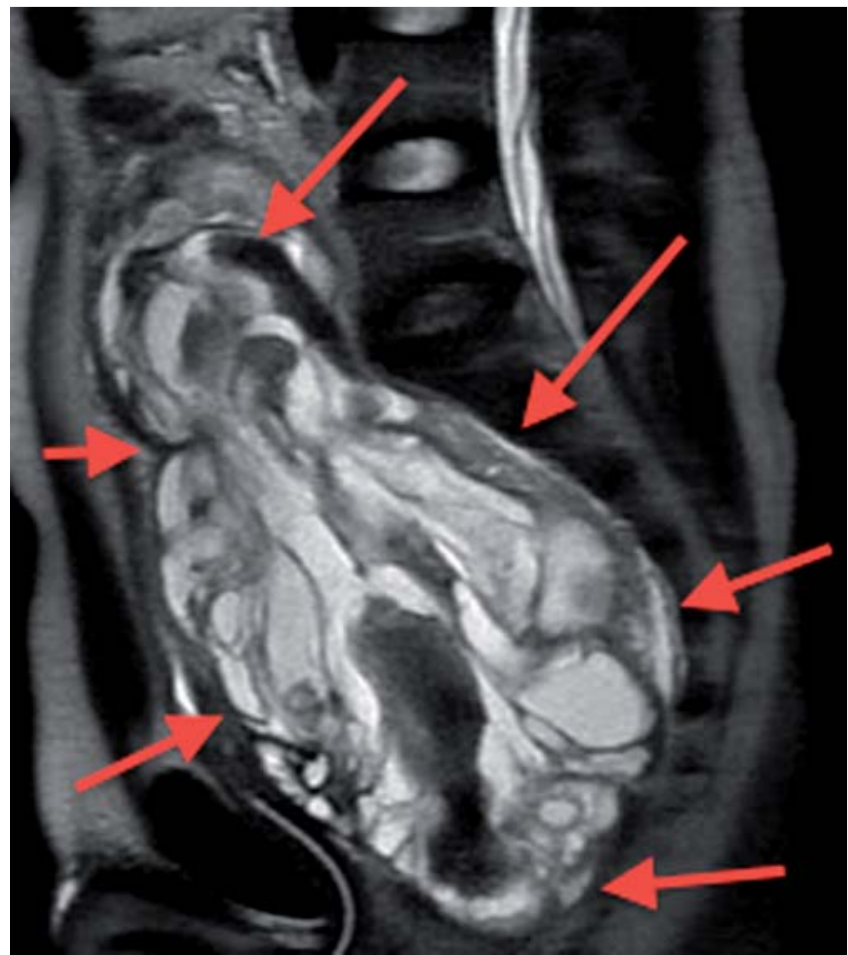

Fig. 1 Magnetic resonance imaging (MRI) scan demonstrating a pelvic and lower abdominal lesion (red arrows) with a sagittal diameter of $25 \mathrm{~cm}$ with relatively sharp, convoluted edges. This extended from the rectum to above the transverse umbilical line.

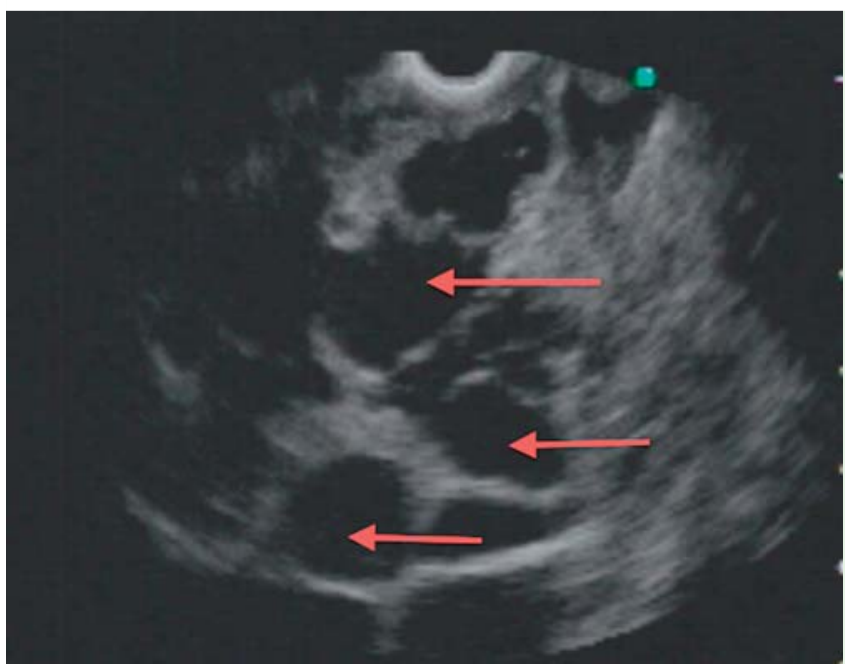

Fig. 2 Endoscopic ultrasound (EUS) image showing a huge circumferential mass in the rectum, with an inhomogeneous echotexture containing multiple anechoic areas (red arrows) consistent with areas of liquefaction.

thermore, we highlight the importance of the EUS-FNA in enabling an early diagnosis of this atypical malignancy to be made. This is the first published report of an early diagnosis of a rectal rhabdomyosarcoma being made by EUS-FNA; therefore, we suggest this technique could be helpful in the diagnosis of rectal masses of unknown origin.
Endoscopy_UCTN_Code_CCL_1AF_2AH

Competing interests: None 


\section{Linea ${ }^{1}$, E. Sinagra² ${ }^{2}$ F. Gioia ${ }^{3}$, C. Rimi ${ }^{4}$}

${ }^{1}$ Gastroenterology Unit, Division of Internal Medicine, Ospedali Riuniti Villa Sofia Cervello, Palermo, Italy

${ }^{2}$ DIBIMIS, Division of Internal Medicine, Ospedali Riuniti Villa Sofia Cervello, Palermo, Italy

${ }^{3}$ Radiology Unit, Division of Internal Medicine, Ospedali Riuniti Villa Sofia Cervello, Palermo, Italy

${ }^{4}$ Pathology Unit, Division of Internal Medicine, Ospedali Riuniti Villa Sofia Cervello, Palermo, Italy

\section{References}

1 Becker V, Gaa J, Ott K et al. A rare case of primary rectal rhabdomyosarcoma in an adult. Z Gastroenterol 2006; 44: 1149-1152

2 Watanabe $Y$, Yamaguchi A, Isogai $M$ et al. Treatment strategies for perianal rhabdomyosarcoma: report of two cases. Surg Today 2004; 34: 719-724

3 Marnewick J, Hulme-Moir M. Embryonal rhabdomyosarcoma of the rectum: report of a case and possible treatment option. Colorectal Dis 2010; 12: e170-e171

\section{Bibliography}

DOI http://dx.doi.org/ 10.1055/s-0032-1309866 Endoscopy 2012; 44: E342-E343

(c) Georg Thieme Verlag KG Stuttgart · New York ISSN 0013-726X

Corresponding author

\section{E. Sinagra, $M D$}

via degli orti 41 90143 Palermo

Italy

Fax: +39-91-6885111

emanuelesinagra83@googlemail.com 